\title{
Solvation of barium atoms and singly charged cations in acetonitrile clusters
}

Martín I. Taccone, Matías Berdakin, Leonardo Baptista, Gustavo A. Pino, and Maximiliano Rossa

Citation: The Journal of Chemical Physics 149, 104308 (2018); doi: 10.1063/1.5044535

View online: https://doi.org/10.1063/1.5044535

View Table of Contents: http://aip.scitation.org/toc/jcp/149/10

Published by the American Institute of Physics

\section{Articles you may be interested in}

Announcement: Top reviewers for The Journal of Chemical Physics 2017

The Journal of Chemical Physics 149, 010201 (2018); 10.1063/1.5043197

Spectroscopy of gold atoms and gold oligomers in helium nanodroplets

The Journal of Chemical Physics 149, 024305 (2018); 10.1063/1.5026480

Perspective: Accurate treatment of the quantum dynamics of light molecules inside fullerene cages:

Translation-rotation states, spectroscopy, and symmetry breaking

The Journal of Chemical Physics 149, 100901 (2018); 10.1063/1.5049358

Photodetachment spectroscopy of cold trapped $\mathrm{NH}_{2}^{-}$near threshold

The Journal of Chemical Physics 149, 104302 (2018); 10.1063/1.5042621

Calculation of vibrational spectroscopic and geometrical characteristics of the $\left[\mathrm{F}(\mathrm{HF})_{2}\right]^{-}$and $\left[\mathrm{F}(\mathrm{DF})_{2}\right]^{-}$ complexes using the second-order vibrational perturbation theory and a $6 \mathrm{D}$ variational method The Journal of Chemical Physics 149, 104306 (2018); 10.1063/1.5042059

Predicted infrared spectra in the HF stretching band of the $\mathrm{H}_{2}-\mathrm{HF}$ complex

The Journal of Chemical Physics 149, 094307 (2018); 10.1063/1.5046359

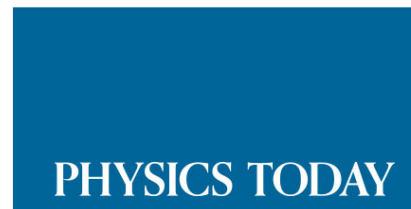




\title{
Solvation of barium atoms and singly charged cations in acetonitrile clusters
}

\author{
Martín I. Taccone, , ${ }^{1,2,3}$ Matías Berdakin, ${ }^{1,2,3, a)}$ Leonardo Baptista, ${ }^{4, b)}$ Gustavo A. Pino, ${ }^{1,2,3}$ \\ and Maximiliano Rossa ${ }^{1,2,3, b)}$ \\ ${ }^{1}$ INFIQC (CONICET-Universidad Nacional de Córdoba), Ciudad Universitaria, X5000HUA Córdoba, \\ Argentina \\ ${ }^{2}$ Dpto. de Fisicoquímica, Facultad de Ciencias Químicas, Universidad Nacional de Córdoba, Ciudad \\ Universitaria, X5000HUA Córdoba, Argentina \\ ${ }^{3}$ Centro Láser de Ciencias Moleculares, Universidad Nacional de Córdoba, Ciudad Universitaria, X5000HUA \\ Córdoba, Argentina \\ ${ }^{4}$ Departamento de Química e Ambiental, Universidade do Estado do Rio de Janeiro, Rodovia Presidente Dutra, \\ KM 298, Resende, Río de Janeiro, Brazil
}

(Received 13 June 2018; accepted 28 August 2018; published online 13 September 2018)

\begin{abstract}
The size distributions of neutral and cationic $\mathrm{Ba}^{x}\left(\mathrm{CH}_{3} \mathrm{CN}\right)_{n}(x=0,+1 ; n \leq 7)$ clusters, as produced by a standard laser vaporization-supersonic expansion pick-up source, were determined from molecular beam experiments. The size distribution for cations is in the range of $n=1-7$, whereas only the $n=1$ complex is observed for neutral clusters, and these two features are unaffected by the variables controlling the performance of the cluster source. The distinct behavior is compatible with the expected charge-dipole interactions in the ionic species, which are stronger than the dipole induced-dipole interactions at play in neutral clusters, and it is corroborated by the relative magnitude of the theoretical successive binding energies (SBEs) for the lowest-lying isomers of cationic and neutral clusters with $n=1-5$, as computed at the density functional theory level. The theoretical results also allow for the rationalization of the bimodal $\mathrm{Ba}^{+}\left(\mathrm{CH}_{3} \mathrm{CN}\right)_{1-7}$ size distribution, featuring an apparent minimum at $n=3$, in terms of chiefly $6 \mathrm{~s}-5 \mathrm{~d} \sigma$ hybridization of the $\mathrm{Ba}^{+}$ions, which ultimately leads to a relatively small third SBE for the $\mathrm{Ba}^{+}\left(\mathrm{CH}_{3} \mathrm{CN}\right)_{3}$ complex, as compared to those for $n=1,2$, and 4. Additional Born-Oppenheimer molecular dynamics simulations on the $\mathrm{Ba}^{+}\left(\mathrm{CH}_{3} \mathrm{CN}\right)_{2-4}$ clusters suggest that all of the ligands are coordinated to the $\mathrm{Ba}^{+}$ion and prevent considering completion of the first solvent shell as responsible for the bimodal size distribution. Published by AIP Publishing. https://doi.org/10.1063/1.5044535
\end{abstract}

\section{INTRODUCTION}

The study of the solvation of group 2 atoms and singly charged cations in gas-phase clusters enables us to probe at the molecular level, the geometries, electronic structures, and energetics of the two charged states, which are formally present in the route from pure metal $\mathrm{M}$ to the doubly charged solvated ions $\mathrm{M}^{2+}$. Neutral atoms featuring a ground-state closed-shell $n \mathrm{~s}^{2}$ configuration display interactions with the solvent molecules, which are dependent on both the identity of the metal atom and the polarity and protic/aprotic nature of the solvent. Hence, the evidence arising from photoionization threshold experiments on $\operatorname{Mg}\left(\mathrm{NH}_{3}\right)_{n}$ clusters suggests that the interactions of a single magnesium atom with clusters of up to $7 \mathrm{NH}_{3}$ molecules are weaker than those between solvent molecules, thereby favoring the formation of the so-called surface structures where the $\mathrm{Mg}$ atom is located preferentially on the surface of a solvent cluster. ${ }^{1}$ Whereas this also holds for small $\mathrm{Mg}\left(\mathrm{H}_{2} \mathrm{O}\right)_{n}(n=1-3)$ clusters, for larger species with

\footnotetext{
a)Present address: Departamento de Física, Facultad de Ciencias Físicas y Matemáticas, Universidad de Chile, Santiago, Chile.

b) Authors to whom correspondence should be addressed: mrossa@ fcq.unc.edu.ar and leobap@gmail.com
}

$n=4-6$, the so-called interior structures, where $\mathrm{Mg}$ is fully coordinated (surrounded) by solvent molecules, appear to be preferred. ${ }^{2}$ For heavier group 2 metals like calcium and barium, the interactions with $\mathrm{H}_{2} \mathrm{O}$ molecules are instead predicted to favor interior clusters even for the smallest sizes attained $(n \leq 4))^{2,3}$ The distinct behavior of $\mathrm{Mg}$ with respect to $\mathrm{Ca}$ and $\mathrm{Ba}$ is likely due to the larger polarizabilities of the latter ${ }^{2}$ since the electron density distributions (associated with the $\mathrm{M}$ valence electron pair) are constrained to the cluster surface region and delocalized over the cluster in surface and interior structures, respectively. ${ }^{4}$

Studies on the microsolvation of group 2 singly charged $\mathrm{M}^{+}$ions consistently suggest that their ground-state open-shell $n \mathrm{~s}^{1}$ configurations cause a strong interaction with molecules of the first solvent shell, leading to most stable structures where the cations are embedded in interior $\mathrm{M}^{+}$(solvent) $)_{n}$ clusters. Such conclusions encompass the interaction of $\mathrm{M}^{+}=\mathrm{Mg}, \mathrm{Ca}$, $\mathrm{Sr}$, and $\mathrm{Ba}$ with a variety of polar and protic/aprotic solvents, including $\mathrm{H}_{2} \mathrm{O}, \mathrm{NH}_{3}, \mathrm{CH}_{3} \mathrm{OH}$, and $\mathrm{CH}_{3} \mathrm{CN}^{5-16}$

The rationalization of photodissociation experiments on $\mathrm{Sr}^{+}$(solvent) ${ }_{n}$ (solvent $\left.=\mathrm{H}_{2} \mathrm{O}, \mathrm{NH}_{3}\right)$ clusters, specially the assignment of linear $\mathrm{O}-\mathrm{Sr}-\mathrm{O}$ and $\mathrm{N}-\mathrm{Sr}-\mathrm{N}$ backbones for $n=2$, required further consideration of s-d $\sigma$ hybridization of the metal atom to reduce the metal-ligand repulsion. ${ }^{7}$ The s-d 
hybridization is also thought to influence the relative ligand binding energies of a number of transition metal ion-solvent complexes, to the extent that their first two binding energies are comparable and much larger than the nearly equal third and fourth binding energies. ${ }^{17}$ No similar, discernible effects of the differential hybridization of group $2 \mathrm{M}^{+}$ions on their stepwise solvation energetics have been reported. The possibility of s-d hybridization is absent in related $\mathrm{Mg}^{+}$(solvent) ${ }_{n}$ clusters, featuring chiefly s-p $\sigma$ hybridization, ${ }^{8}$ which is reminiscent of transition metal ion-solvent complexes in which only s-d $\sigma$ hybridization is involved in reducing metal-ligand repulsion. ${ }^{17-19}$

The present work reports on a determination of the size distributions of neutral and cationic $\mathrm{Ba}^{x}\left(\mathrm{CH}_{3} \mathrm{CN}\right)_{n}(x=0,+1$; $n \leq 7)$ clusters, as derived from molecular beam experiments probing sequentially the neutral and the singly charged states. The clusters were produced by a standard laser vaporizationsupersonic expansion pick-up source. The experimental results are complemented with density functional theory (DFT) calculations of the structure, successive ligand binding energies, and adiabatic and vertical ionization energies $\left(\mathrm{IE}_{v}\right.$ 's) for the lowest-lying isomers of neutral and cationic clusters with $n=1-5$. Also, Born-Oppenheimer Molecular Dynamics (BOMD) were performed on the lowest-lying isomers of $\mathrm{Ba}^{+}\left(\mathrm{CH}_{3} \mathrm{CN}\right)_{2-4}$ clusters to assess the structure of the corresponding first and second solvent shells and the reorganization of acetonitrile molecules between them. The theoretical results provide information on the energetics of the stepwise solvation process of $\mathrm{Ba}$ and $\mathrm{Ba}^{+}$species in small acetonitrile clusters, as well as on the electronic structure of the interior structures of the corresponding first solvation shells.

\section{EXPERIMENTAL AND THEORETICAL METHODS}

$\mathrm{Ba}^{x}\left(\mathrm{CH}_{3} \mathrm{CN}\right)_{n}$ clusters $(x=0$ for neutrals and $x=+1$ for cations) were generated in a pick-up source combining $1064 \mathrm{~nm}$ laser vaporization of a rotating Ba disk, ${ }^{3}$ with a supersonic expansion of a gaseous $\mathrm{He}: \mathrm{CH}_{3} \mathrm{CN}$ (0.944:0.056) mixture through a pulsed solenoid valve ( $200 \mu$ m diameter $)$ at a stagnation pressure of 2 bars. The cluster beam was collimated with a $1.0 \mathrm{~mm}$ slit skimmer placed $10 \mathrm{~cm}$ downstream from the nozzle before entering the extraction/acceleration region of a Wiley-McLaren time-of-flight mass spectrometer (TOF-MS) (80 cm flight length). ${ }^{3}$

The nascent neutral clusters were ionized in the extraction region by the second, third, or fourth harmonics (532, 355 , or $266 \mathrm{~nm}$, respectively) of a pulsed Nd:YAG laser, and the resulting ions were extracted by applying a continuous high voltage to the extraction plates. ${ }^{3}$ Additional experiments were performed in a wider range of ionization laser fluences to get estimates on the laser power dependence of the various species observed in the mass spectra. The detection of the nascent cationic clusters was instead carried out in the absence of any ionization laser. To avoid the repulsion of the ions at the entrance of the extraction region, the extraction voltages were maintained at $0 \mathrm{~V}$. The extraction of the ions was achieved by applying high voltage pulses of $5 \mu$ s duration to the extraction and repulsion plates in synchronization with the arrival of the $\mathrm{Ba}^{+}\left(\mathrm{CH}_{3} \mathrm{CN}\right)_{n}$ clusters to the center of the extraction region.

In the detection schemes of both neutral and cationic clusters, the ions that were extracted/accelerated into the TOFMS have been further detected by a dual microchannel plate (MCP), and its output signal was digitized and afterwards processed in a personal computer. An average of 512 laser vaporization/supersonic expansion pulses was used to generate the mass spectra.

Quantum chemistry calculations on both the lowestlying isomers of $\mathrm{Ba}^{x}\left(\mathrm{CH}_{3} \mathrm{CN}\right)_{1-5}$ clusters and the ground-state $\mathrm{BaNC}^{x}$ and $\mathrm{BaCN}^{x}$ species were carried out using the Gaussian 09 suite of programs. ${ }^{20}$ The structures were optimized, and their harmonic vibrational frequencies were computed through the mPW1PW91 method of the density functional theory (DFT). ${ }^{21}$ The 6-311G(d,p) basis sets were used for the C, $\mathrm{N}$, and $\mathrm{H}$ atoms, along with the relativistic effective core potential (RECP) developed by Lim et al. ${ }^{22}$ and its corresponding $13 s 12 p 6 d 4 f 2 g$ uncontracted basis set for Ba.

The DFT approach was chosen on the basis of a previous study from this laboratory addressing to the photoionization of $\mathrm{Ba}\left(\mathrm{H}_{2} \mathrm{O}\right)_{n}$ clusters, ${ }^{3}$ where in addition to mPW1PW91, three hybrid functionals had been evaluated, i.e., B3LYP, M06$2 \mathrm{X}$, and the long range-corrected version of the functional wPBE, i.e, LC-wPBE, as defined in the Gaussian 09 package. As well, for $\mathrm{Ba}$ atoms, a number of pseudo-potentials (and their corresponding valence basis sets) were tried, such as SDD, CEP-121G, and LanL2DZ, as defined in the Gaussian 09 software and the RECP's developed by Lim et al., ${ }^{22}$ and by Bauschlicher et al. ${ }^{23,24}$ The mPW1PW91/Lim et al.'s RECP combination [along with the 6-311++G(d,p) basis set for $\mathrm{O}$ and $\mathrm{H}$ atoms] led to the best agreement with the experiments. ${ }^{3}$ A further, related study on $\mathrm{BaOH}\left(\mathrm{H}_{2} \mathrm{O}\right)_{n}$ clusters (Ref. 25) added support for this theoretical approach to suitably describe systems, which are characterized by covalent and non-covalent interactions, including van der Waals interactions. ${ }^{21}$

The successive binding energies (SBEs) for the solvation processes, $\mathrm{Ba}^{x}\left(\mathrm{CH}_{3} \mathrm{CN}\right)_{n-1}+\mathrm{CH}_{3} \mathrm{CN} \rightarrow \mathrm{Ba}^{x}\left(\mathrm{CH}_{3} \mathrm{CN}\right)_{n}$, were estimated as

$$
\begin{aligned}
E_{\text {bind }}(n)= & E\left[\mathrm{Ba}^{x}\left(\mathrm{CH}_{3} \mathrm{CN}\right)_{n}\right]-E\left[\mathrm{Ba}^{x}\left(\mathrm{CH}_{3} \mathrm{CN}\right)_{n-1}\right] \\
& -E\left[\mathrm{CH}_{3} \mathrm{CN}\right],
\end{aligned}
$$

where $E\left[\mathrm{Ba}^{x}\left(\mathrm{CH}_{3} \mathrm{CN}\right)_{n}\right], E\left[\mathrm{Ba}^{x}\left(\mathrm{CH}_{3} \mathrm{CN}\right)_{n-1}\right]$, and $E\left[\mathrm{CH}_{3} \mathrm{CN}\right]$ denote the total electronic energies, including zero-point energy (ZPE) corrections, of the relevant species. Armentrout and coworkers have recently shown that a reasonable agreement with experimental values of the binding energies for $\mathrm{Ba}^{2+}\left(\mathrm{H}_{2} \mathrm{O}\right)_{1-8}$ clusters, as determined by using the threshold collision-induced dissociation technique, can be obtained from a DFT/B3LYP treatment, using the Lim et al.'s RECP for $\mathrm{Ba}^{2+}$ and a balanced basis set [def2-TZVPP] for the $\mathrm{O}$ and $\mathrm{H}$ atoms. ${ }^{26}$ Hence, the theoretical treatment at the DFT level used here seems suitable for getting estimates on the cluster size dependence of $E_{\text {bind }}$ for the $\mathrm{Ba}^{x}\left(\mathrm{CH}_{3} \mathrm{CN}\right)_{1-4}$ family clusters.

Vertical ionization energies ( $\mathrm{IE}_{v}$ 's) of the neutral $\mathrm{Ba}\left(\mathrm{CH}_{3} \mathrm{CN}\right)_{n}$ clusters were computed as the difference in total electronic energies, including ZPE corrections, between the 
cationic and neutral species, both computed at the optimized structures of the neutral clusters. Adiabatic ionization energies ( $\mathrm{IE}_{a}$ 's) of the $\mathrm{Ba}\left(\mathrm{CH}_{3} \mathrm{CN}\right)_{n}$ and the $\mathrm{BaNC} / \mathrm{BaCN}$ species were instead referenced to the optimized geometries of the cationic and the neutral species.

BOMD calculations were performed on the $\mathrm{Ba}^{+}\left(\mathrm{CH}_{3} \mathrm{CN}\right)_{2-4}$ clusters. In all of the cases, the cluster dynamics were evaluated at a temperature of $298 \mathrm{~K}$, while for $n=2$, additional calculations were performed at 0 and $50 \mathrm{~K}$. The simulation time was set to 1000 steps, which correspond to up to $700 \mathrm{fs}$ of simulation, and the Hessian was fully calculated at every 20 steps of simulation. A single simulation was conducted for the $n=3$ and 4 clusters since previous work showed that the trajectories will change only if the initial conditions change. $^{27,28}$

\section{RESULTS AND DISCUSSION}

\section{A. Cationic clusters: $\mathrm{Ba}^{+}\left(\mathrm{CH}_{3} \mathrm{CN}\right)_{n}$}

Due to the wider cluster size distribution for cations, as compared to neutral species (see below), the results for the charged species will be discussed first. The upper panel of Fig. 1 shows a typical mass spectrum of the cationic species, which are contained in the barium-acetonitrile cluster beam. It is dominated by the $\mathrm{Ba}^{+}\left(\mathrm{CH}_{3} \mathrm{CN}\right)_{1-7}$ clusters, in addition to a minor proportion of $\mathrm{BaNC}^{+}\left(\mathrm{CH}_{3} \mathrm{CN}\right)_{1-6}$ and
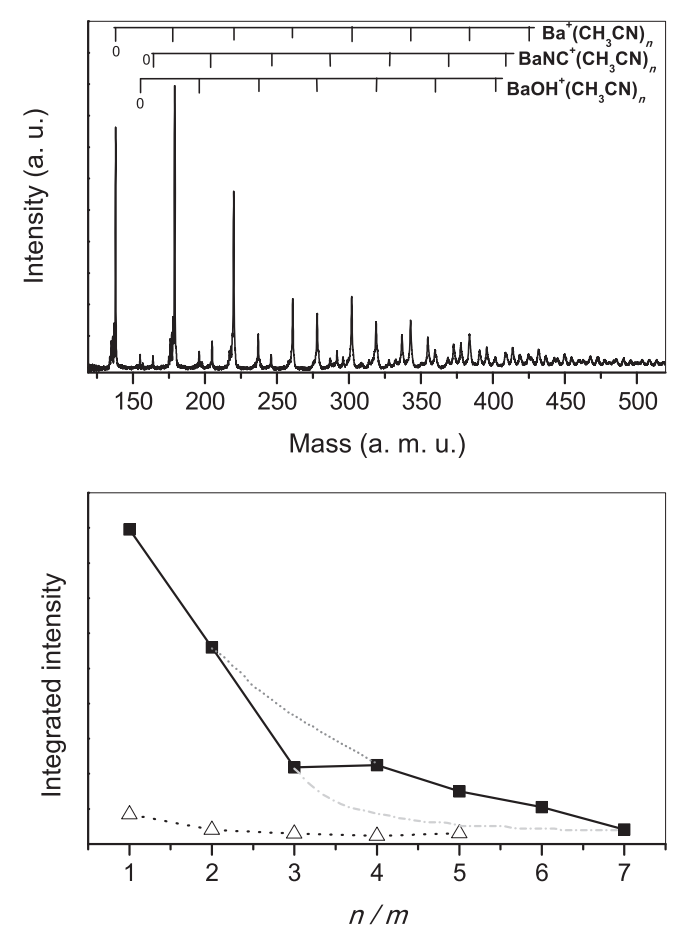

FIG. 1. Upper panel: Typical mass spectrum of the nascent $\mathrm{Ba}^{+}\left(\mathrm{CH}_{3} \mathrm{CN}\right)_{n}$, $\mathrm{BaNC}^{+}\left(\mathrm{CH}_{3} \mathrm{CN}\right)_{n}$, and $\mathrm{BaOH}^{+}\left(\mathrm{CH}_{3} \mathrm{CN}\right)_{n}$ cluster ions produced in the cluster beam. For these cluster families, the combs mark the position of the mass peaks associated with the barium 138 isotopic component for each cluster size, $n$. Lower panel: Integrated intensities of the ${ }^{138} \mathrm{Ba}^{+}\left(\mathrm{CH}_{3} \mathrm{CN}\right)_{1-7}(\mathbf{\square})$ and ${ }^{138} \mathrm{BaNC}^{+}\left(\mathrm{CH}_{3} \mathrm{CN}\right)_{1-5}(\triangle)$ peaks as a function of $n$. As a guide to the eye, a dotted line $(\cdots)$ linking $n=2$ and 4 is drawn to depict the expected evolution for ${ }^{138} \mathrm{Ba}^{+}\left(\mathrm{CH}_{3} \mathrm{CN}\right)_{1-7}$ peaks, by assuming a continuously decreasing cluster size distribution, along with a dashed-dotted line (.-.) linking $n=3$ and 7 to show the expected evolution based on an extrapolation of the integrated intensities from the ${ }^{138} \mathrm{Ba}^{+}\left(\mathrm{CH}_{3} \mathrm{CN}\right)_{1-3}$ peaks.
$\mathrm{BaOH}^{+}\left(\mathrm{CH}_{3} \mathrm{CN}\right)_{1-6}$. For each size of these family clusters, five mass peaks are observed, which correspond to the most abundant barium 138, 137, 136, 135, and 134 isotopic components. The $\mathrm{BaNC}^{+}$(or $\mathrm{BaCN}^{+}$) and $\mathrm{BaOH}^{+}$species are presumably products of the reaction in the cluster source between $\mathrm{Ba}^{+}$ ions and molecules of acetonitrile and with impurities (mainly water), respectively. ${ }^{29}$ These species then become solvated in acetonitrile clusters, most likely by the evaporative process: $\mathrm{BaNC}^{+} / \mathrm{BaOH}^{+}+\left(\mathrm{CH}_{3} \mathrm{CN}\right)_{n+1} \rightarrow \mathrm{BaNC}^{+} / \mathrm{BaOH}^{+}\left(\mathrm{CH}_{3} \mathrm{CN}\right)_{n}$ $+\mathrm{CH}_{3} \mathrm{CN} .^{25}$

The lower panel of Fig. 1 shows the relative populations of the $\mathrm{Ba}^{+}\left(\mathrm{CH}_{3} \mathrm{CN}\right)_{n}$ and $\mathrm{BaNC}^{+}\left(\mathrm{CH}_{3} \mathrm{CN}\right)_{n}$ families as a function of $n$, as derived from the integrated intensities of the mass peaks corresponding to their dominant barium 138 isotopic components. For both families, the lightest clusters with $n=1,2$ are favored over larger members. Yet, a difference is observed: Whereas the $\mathrm{BaNC}^{+}\left(\mathrm{CH}_{3} \mathrm{CN}\right)_{n}$ peak intensities steadily decrease in the range of $n=1-5$, in the case of $\mathrm{Ba}^{+}\left(\mathrm{CH}_{3} \mathrm{CN}\right)_{n}$, the peak for $n=3$ appears too low in intensity, as compared to an otherwise continuously decreasing cluster size distribution. Such a feature confers the $\mathrm{Ba}^{+}\left(\mathrm{CH}_{3} \mathrm{CN}\right)_{n}$ cluster population the appearance of a bimodal size distribution, consisting of a progressively decreasing distribution for small clusters, $n=1-3$, and a broader distribution for larger clusters, $n \geq 3$, with an apparent maximum at $n=4$. Given the distinct behavior of the $\mathrm{Ba}^{+}\left(\mathrm{CH}_{3} \mathrm{CN}\right)_{n}$ size population, only this cluster family will be discussed hereafter.

The $\mathrm{Ba}^{+}\left(\mathrm{CH}_{3} \mathrm{CN}\right)_{n}$ size distribution was found to be unaffected by a number of variables controlling the performance of the cluster source, such as the stagnation pressure of the pulsed valve (1-4 bars), the distance between the axis of the supersonic expansion and the vaporization laser spot on the Ba sample (1-5 mm), and the vaporization laser fluence (in the absence of visible plasma). On this basis, the possibility that the $\mathrm{Ba}^{+}\left(\mathrm{CH}_{3} \mathrm{CN}\right)_{n}$ distribution results from the relative binding energies of the various cluster sizes has been explored by ab initio calculations, which focused chiefly on the energetics of the lowest-lying isomers for $n=1-4$ as larger clusters show a monotonically decreasing size distribution. The resulting, most stable geometries are shown in Fig. 2, and the corresponding, successive binding energies for solvation in acetonitrile are listed in Table I. The SBE values corrected for the basis set superposition error (BSSE) through the counterpoise method, as implemented in the Gaussian 09 package, ${ }^{20}$ are also reported in Table I. It is worth noticing that the corrections are 6.0, 6.1, 5.7, and $10.9 \mathrm{~kJ} \mathrm{~mol}^{-1}$ for $n=1,2,3$, and 4, respectively, which are lower than the precision of the present theoretical methodology.

The optimized geometries for the $\mathrm{BaNC}^{+}$and the $\mathrm{BaCN}^{+}$ species are also shown in Fig. 2, as they are used to calculate the $\mathrm{IE}_{a}$ 's of BaNC and BaCN (see Sec. III B). Note that $\mathrm{BaNC}^{+}$and $\mathrm{BaNC}$ are found here to be lower in energy than $\mathrm{BaCN}^{+}$and $\mathrm{BaCN}$ by 0.31 and $0.23 \mathrm{eV}$, respectively, which agrees with the energy difference between BaNC and $\mathrm{BaCN}$ of $0.20 \mathrm{eV}$, as computed previously at the configuration interaction with the single and double excitation method by Bauschlicher et al. ${ }^{30}$ Hence, the notation $\mathrm{BaNC}^{+}$and BaNC is preferred hereafter, although we are not able to ensure what 
$\mathrm{Ba}^{+}\left(\mathrm{CH}_{3} \mathrm{CN}\right)_{1}$
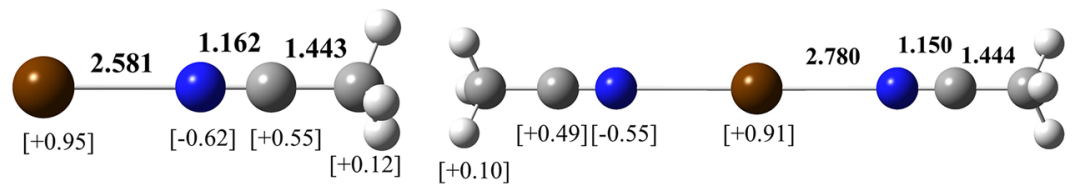

$\mathrm{Ba}^{+}\left(\mathrm{CH}_{3} \mathrm{CN}\right)_{2}$

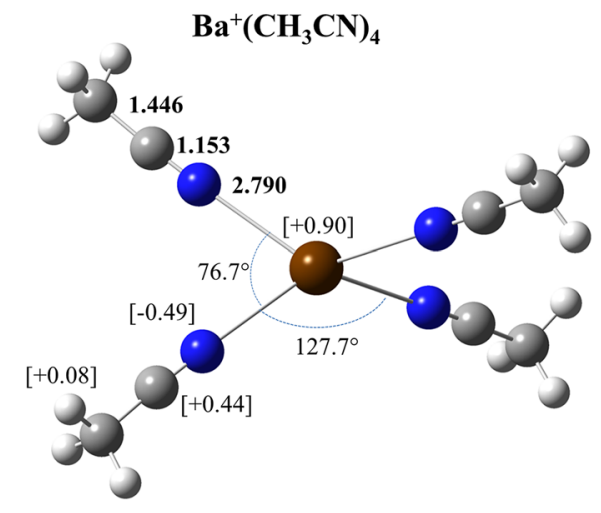

FIG. 2. Optimized structures for the lowest-lying energy isomers of cationic $\mathrm{Ba}^{+}\left(\mathrm{CH}_{3} \mathrm{CN}\right)_{1-4}$ clusters, as calculated at the $m$ PW1PW91 level. The bond lengths and the bond angles are given in angstroms and degrees, respectively. The results of natural population analysis at the DFT level are indicated in brackets.
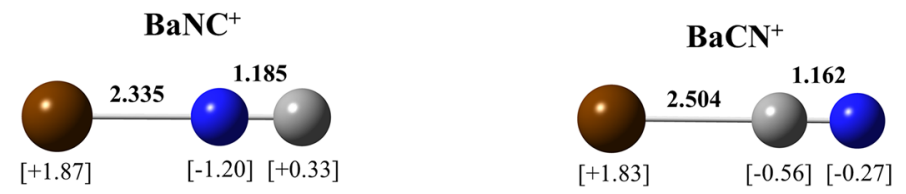

isomer (isocyanide or cyanide) of these species is present in the experiments.

The $\mathrm{Ba}^{+}\left(\mathrm{CH}_{3} \mathrm{CN}\right)_{n}$ theoretical structures show up a preference for the $\mathrm{Ba}^{+}$ions to coordinate to the $\mathrm{N}$ atoms of acetonitrile molecules. This is to be expected from the relatively large dipole moment of acetonitrile $(3.93 \mathrm{D})^{31}$ concentrating the negative charge on the $\mathrm{N}$-end and from the lone pair of electrons located on the nitrogen atom. The clusters with $n=1$ and 2 have linear configurations, where the axes of the corresponding $\mathrm{CH}_{3} \mathrm{CN}$ molecules are aligned with the $\mathrm{Ba}^{+}$ions leading to $\mathrm{C}_{3 v}$ and $\mathrm{D}_{3 d}$ (i.e., the two $\mathrm{CH}_{3}$ groups staggered) symmetries, respectively.

For $n=3$, a planar structure was found, in which two $\mathrm{CH}_{3} \mathrm{CN}$ molecules are coordinated to the $\mathrm{Ba}^{+}$ion with a $\mathrm{N}-\mathrm{Ba}-\mathrm{N}$ angle of $94.4^{\circ}$, and the third $\mathrm{CH}_{3} \mathrm{CN}$ molecule lies on the opposite side of the metal atom, pointing to it along the bisector angle of the former two ligands. For $n=4$, the $\mathrm{Ba}^{+}$ion is coordinated to the $\mathrm{N}$-ends of the four $\mathrm{CH}_{3} \mathrm{CN}$ molecules in a distorted tetrahedral geometry, featuring two

TABLE I. Theoretical successive binding energies (SBEs) for the solvation processes, $\mathrm{Ba}^{x}\left(\mathrm{CH}_{3} \mathrm{CN}\right)_{n-1}+\mathrm{CH}_{3} \mathrm{CN} \rightarrow \mathrm{Ba}^{x}\left(\mathrm{CH}_{3} \mathrm{CN}\right)_{n}$, as calculated at the $m$ PW1PW91 level. Values corrected for BSSE through the counterpoise method are indicated in brackets.

\begin{tabular}{lcc}
\hline \hline & \multicolumn{2}{c}{ SBEs $\left(\mathrm{kJ} \mathrm{mol}^{-1}\right)$} \\
\cline { 2 - 3 }$n$ & $x=+1$ & $x=0$ \\
\hline 1 & $-130.4(124.4)$ & $-35.6(29.7)$ \\
2 & $-114.3(108.2)$ & $-38.2(32.1)$ \\
3 & $-78.6(72.9)$ & $-27.6(23.5)$ \\
4 & $-120.8(109.9)$ & $-35.5(31.3)$ \\
\hline \hline
\end{tabular}

pairs of acetonitrile molecules at $\mathrm{N}-\mathrm{Ba}-\mathrm{N}$ angles of $127.7^{\circ}$ and a $\mathrm{N}-\mathrm{Ba}-\mathrm{N}$ angle of $76.7^{\circ}$ between two closest $\mathrm{CH}_{3} \mathrm{CN}$ molecules.

An assessment of previous results for the $\mathrm{Mg}^{+}\left(\mathrm{CH}_{3} \mathrm{CN}\right)_{1-3}$ system can help to rationalize the theoretical structures of the lowest-lying isomers of $\mathrm{Ba}^{+}\left(\mathrm{CH}_{3} \mathrm{CN}\right)_{1-4}$ clusters. The $\mathrm{Mg}^{+}\left(\mathrm{CH}_{3} \mathrm{CN}\right)_{n}$ structures for $n=1,2$, and 3, respectively, as computed at the B3LYP/6-31+G $\mathrm{G}^{* *}$ level, ${ }^{15}$ feature $\mathrm{C}_{3 v}, \mathrm{C}_{2 v}$, and $\mathrm{C}_{3 v}$ symmetries, with all of the acetonitrile molecules in the first solvent shell. These geometries can be interpreted in terms of $3 \mathrm{~s}-3 \mathrm{p} \sigma$ hybridization of the $\mathrm{Mg}^{+}$ion, along with the location of the valence unpaired electron in one of the s-p $\sigma$ orbitals. $^{8}$ Such unpaired electron density distribution polarizes away from the electron clouds of the ligands, which locate on the opposite side of the $\mathrm{Mg}^{+}$ion and allocate their $\mathrm{N}$-end lone pairs of electrons on the remaining hybrid orbitals. This explains the $\mathrm{N}-\mathrm{Mg}-\mathrm{N}$ angles of $96.7^{\circ}$ and $97.4^{\circ}$, which characterize the geometries of $\mathrm{Mg}^{+}\left(\mathrm{CH}_{3} \mathrm{CN}\right)_{2,3}$.

The rationalization of the $\mathrm{Ba}^{+}\left(\mathrm{CH}_{3} \mathrm{CN}\right)_{n}$ structures requires additional consideration of $6 s-5 d \sigma$ hybridization of the $\mathrm{Ba}^{+}$ion, along with the location of the unpaired electron in one of the s-d $\sigma$ orbitals, i.e., the one localized perpendicular to the $\sigma$ axis. ${ }^{8}$ This is to be expected from the ${ }^{2} D$ state of $\mathrm{Ba}^{+}$lying below its ${ }^{2} P$ state ${ }^{32}$ and confirmed by computing, via natural population analysis, the s:d barium ion atomic orbital contribution to the singly occupied molecular orbitals (SOMO's) of the complexes (Fig. 3). The contribution values obtained are 0.86:0.12, 0.75:0.25, $0.61: 0.37$, and $0.45: 0.36$, for $n=1,2,3$, and 4, respectively. The remaining s-d $\sigma$ orbitals are localized perpendicularly to the SOMO's and can allocate the ligand's lone pairs of electrons. 

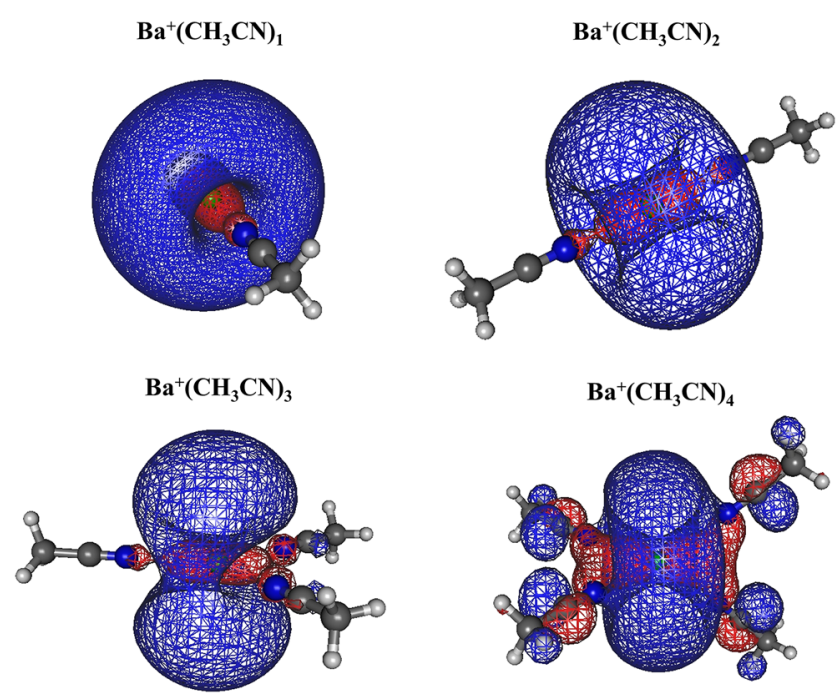

FIG. 3. Electronic density distributions of the SOMO's in the lowestlying energy isomers of $\mathrm{Ba}^{+}\left(\mathrm{CH}_{3} \mathrm{CN}\right)_{1-4}$ clusters. The iso-density surfaces correspond to $0.015 \AA^{-3}$.

For $n=2$, the two $\mathrm{CH}_{3} \mathrm{CN}$ molecules can donate electrons to the same s-d $\sigma$ hybrid orbital, thereby sharing the energetic cost of hybridization and favoring a linear $\mathrm{N}-\mathrm{Ba}-\mathrm{N}$ configuration. It is found that the $\mathrm{Ba}-\mathrm{N}$ distance for $n=2$ is longer than for 1 and that the second SBE is smaller than the first one. Such trends in bond lengths and in SBEs are opposite to those for complexes of many transitionmetal ions, where only s-d $\sigma$ hybridization is operative to reduce the metal-ligand repulsion. ${ }^{17-19}$ This is indicative of either a residual metal-ligand repulsion or the additional involvement of s-p (6s-6p) $\sigma$ hybridization in the bonding of $\mathrm{Ba}^{+}\left(\mathrm{CH}_{3} \mathrm{CN}\right)_{1}$, as suggested previously for the $\mathrm{Sr}^{+}\left(\mathrm{H}_{2} \mathrm{O}\right)_{1}$ complex. $^{8}$

It has usually been reported for transition-metal ion complexes that the third and fourth SBEs are both nearly equal and significantly smaller than the first two SBEs, which in turn are comparable to each other. This is ascribed to the increased repulsion between the electron density of the SOMO and the lone pairs of electrons of the third and fourth ligands due to their location around the metal ion. ${ }^{17}$ In the $\mathrm{Ba}^{+}\left(\mathrm{CH}_{3} \mathrm{CN}\right)_{n}$ system, the fourth SBE is instead larger than the third and has an intermediate value between the magnitudes of the first and the second SBEs. It is apparent that the four $\mathrm{CH}_{3} \mathrm{CN}$ ligands, in $n=4$, share the energetic cost of s-d hybridization by locating two pairs of ligands in a distorted tetrahedral geometry. In addition to reducing the metal-ligand repulsion, such a geometry likely leads to favorable interaction between the induced quadrupole moment on $\mathrm{Ba}^{+}$(due to s-d $\sigma$ hybridization) and the net dipole moment, which results from the arrangement of acetonitrile molecules around the metal ion. 8

In the lowest-lying $\mathrm{Ba}^{+}\left(\mathrm{CH}_{3} \mathrm{CN}\right)_{3}$ isomers, the location of the three ligands in a planar configuration seemingly minimizes the electron repulsion between the ligands and the SOMO. Yet, the interaction between ligands and the induced quadrupole moment on $\mathrm{Ba}^{+}$is not as favorable as in the cases for $n=2$ and 4 , which could be the reason of the relatively small third SBE.
Hence, the above theoretical results allow for the rationalization of the bimodal $\mathrm{Ba}^{+}\left(\mathrm{CH}_{3} \mathrm{CN}\right)_{n}$ cluster size distribution in terms of the SBEs of the lowest-lying isomers of $\mathrm{Ba}^{+}\left(\mathrm{CH}_{3} \mathrm{CN}\right)_{1-4}$ clusters, from which it could be expected for the $\mathrm{Ba}^{+}\left(\mathrm{CH}_{3} \mathrm{CN}\right)_{3}$ complex to have a low population, as compared to those for $n=1,2$, and 4 .

It is also important to mention that, as expected, the number of low-lying energy structures for clusters larger than $n=4$ increases significantly with increasing $n$. To keep the system computationally treatable, only the low-lying conformations of the $\mathrm{Ba}^{+}\left(\mathrm{CH}_{3} \mathrm{CN}\right)_{5}$ cluster were explored, and the most stable geometry found in this work features the five acetonitrile molecules coordinated to the $\mathrm{Ba}^{+}$ion (Fig. S. 1 of the supplementary material). Out of these, three acetonitriles are arranged in a distorted $\mathrm{T}$ structure and lying on one side of the $\mathrm{Ba}^{+}$ion, with the remaining two $\mathrm{CH}_{3} \mathrm{CN}$ molecules roughly polarized on the opposite side, where the valence (unpaired) electron is found to be delocalized (Fig. S.2 of the supplementary material). More importantly, the corresponding $E_{\text {bind }}$ for solvation in acetonitrile is derived to be $79.1 \mathrm{~kJ} \mathrm{~mol}^{-1}$, which is lower than the binding energies for the most stable isomers of the $\mathrm{Ba}^{+}\left(\mathrm{CH}_{3} \mathrm{CN}\right)_{1,2,4}$ clusters and compatible with the relative population of $\mathrm{Ba}^{+}\left(\mathrm{CH}_{3} \mathrm{CN}\right)_{5}$ in the cluster size distribution. The $E_{\text {bind }}$ of $\mathrm{Ba}^{+}\left(\mathrm{CH}_{3} \mathrm{CN}\right)_{5}$ has a contribution from the interaction between the $\mathrm{d}$ orbitals of $\mathrm{Ba}^{+}$and the orbitals derived from the $\mathrm{N} \equiv \mathrm{C}$ groups of the two closest $\mathrm{CH}_{3} \mathrm{CN}$ molecules, especially the one having a $\mathrm{N}-\mathrm{C}-\mathrm{C}$ angle that deviates from linearity $\left(134.7^{\circ}\right)$. It is confirmed by computing the atomic orbital contribution to the SOMO of $\mathrm{Ba}^{+}\left(\mathrm{CH}_{3} \mathrm{CN}\right)_{5}$ (Fig. S.2), which leads to values of 0.11 for the $\mathrm{d}$ barium ion orbital and 0.29 and 0.25 for the p orbitals of the $\mathrm{N}$ and $\mathrm{C}$ atoms, respectively. This suggests that the s-d hybridization is lost with the addition of the fifth acetonitrile, and thus the interaction between $\mathrm{Ba}^{+}$and the relevant $\mathrm{N} \equiv \mathrm{C}$ group strengthens (i.e., the $\mathrm{N} \equiv \mathrm{C}$ group acts as a single atom- "halogen analogue").

\section{B. Neutral clusters: $\mathrm{Ba}\left(\mathrm{CH}_{3} \mathrm{CN}\right)_{n}$}

Figure 4 shows typical mass spectra of the neutral species entrained in the molecular beam, as recorded at three laser ionization energies. The only barium-acetonitrile cluster observed is $\mathrm{Ba}\left(\mathrm{CH}_{3} \mathrm{CN}\right)_{1}$, which at the photon energy of $4.66 \mathrm{eV}$ is detected under single-photon ionization conditions, but it is not discernible at 3.49 and $2.33 \mathrm{eV}$. Such narrow cluster size distributions were found to be unaffected by the variables controlling the performance of the cluster source, likewise for cluster cations (see Sec. III A).

In addition, photoionized $\mathrm{Ba}$ atoms (IE $=5.21 \mathrm{eV}$; Ref. 31) and various molecular species like BaNC (or $\mathrm{BaCN}$ ), both naked and complexed by one acetonitrile molecule, $\mathrm{BaCC}$, $\mathrm{BaOH}$, and $\mathrm{BaO}$, are observed at the three photoionization energies used in this work. The parent neutral molecular species are presumably generated as byproducts in the cluster source (Sec. III A). For each of these species, as well as for the $\mathrm{Ba}\left(\mathrm{CH}_{3} \mathrm{CN}\right)_{1}$ complex, five mass peaks are observed, which correspond to the most abundant barium 138, 137, 136, 135, and 134 isotopic components.

The dominant $\mathrm{BaNC}^{+}$mass peak detected at $2.33 \mathrm{eV}$ photoionization energy parallels observations made previously 


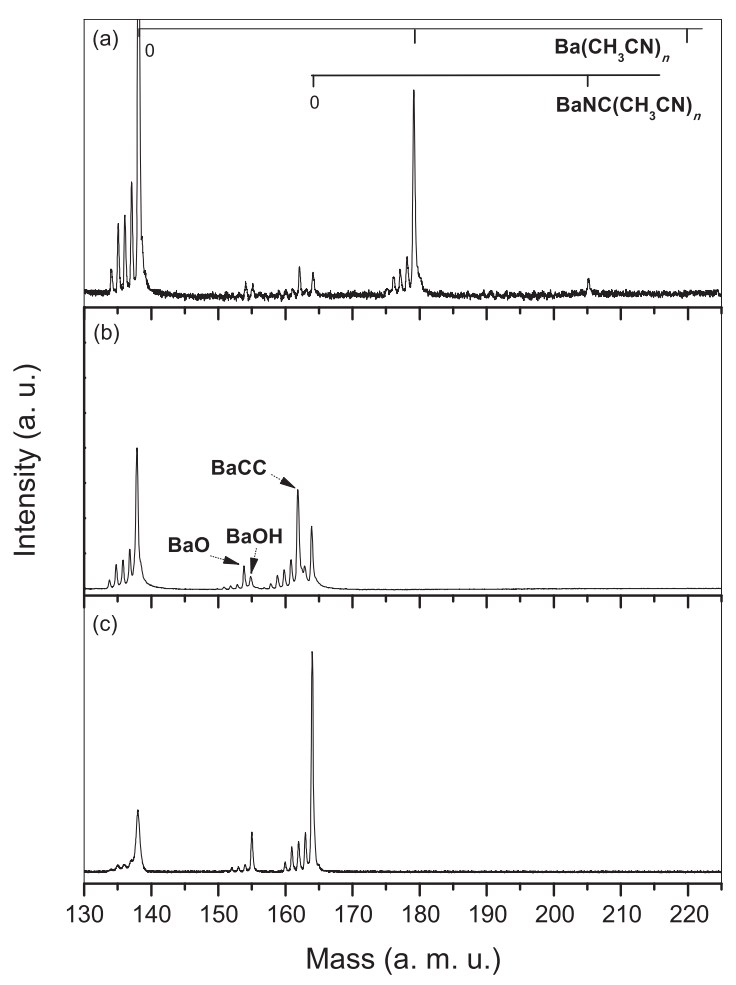

FIG. 4. Typical mass spectra of the neutral $\mathrm{Ba}\left(\mathrm{CH}_{3} \mathrm{CN}\right)_{n}$ and $\mathrm{BaNC}\left(\mathrm{CH}_{3} \mathrm{CN}\right)_{n}$ species produced in the cluster beam, as photoionized at (a) $4.66 \mathrm{eV}$, (b) $3.49 \mathrm{eV}$, and (c) $2.33 \mathrm{eV}$. Other molecular species are observed as well, as indicated in panel (b). For all of these species, the combs in (a) and the arrows in (b) mark the position of the mass peaks, which are associated with the corresponding barium 138 isotopic component.

upon resonant multiphoton ionization (MPI) in the range of 2.23-2.42 eV of the species entrained in a barium-acetonitrile molecular beam, as produced in a pick-up source under similar conditions as here. ${ }^{33}$ Although the $\mathrm{IE}_{a}$ 's of BaNC and $\mathrm{BaCN}$ calculated in this work, of 5.19 and $5.28 \mathrm{eV}$, respectively, are higher than that of $\mathrm{Ba}\left(\mathrm{CH}_{3} \mathrm{CN}\right)_{1}\left(\mathrm{IE}_{a}=4.12 \mathrm{eV}\right.$; see Table II) or $\mathrm{BaOH}\left(\mathrm{IE}_{a}=4.55 \mathrm{eV}\right.$; Ref. 29), the intensity of the mass peak corresponding to $\mathrm{BaNC}+\mathrm{BaCN}+$ is the highest upon photoionization at $2.3 \mathrm{eV}$ [Fig. 4(c)] due to the fact that this wavelength is resonant with an excited electronic state $\left(\mathrm{C}^{2} \Pi-\mathrm{X}^{2} \Sigma^{+}\right.$; Ref. 33) of neutral BaNC/BaCN. Instead, the signals from the other molecular species arise from less efficient, non-resonant MPI processes, thereby leading to lower intensities of the corresponding mass peaks.

Like for the charged species, density functional calculations have been performed on the lowest-lying isomers of neutral $\mathrm{Ba}\left(\mathrm{CH}_{3} \mathrm{CN}\right)_{1-4}$ clusters, for which the most stable

TABLE II. Theoretical vertical $\left(\mathrm{IE}_{v}\right)$ and adiabatic $\left(\mathrm{IE}_{a}\right)$ ionization energies (in eV) for the lowest-lying energy isomers of neutral $\mathrm{Ba}\left(\mathrm{CH}_{3} \mathrm{CN}\right)_{n}(n=0-4)$ clusters, as calculated at the $m$ PW1PW91 level.

\begin{tabular}{lll}
\hline \hline$n$ & $\mathrm{IE}_{v}$ & $\mathrm{IE}_{a}$ \\
\hline 1 & 4.12 & 4.12 \\
2 & 3.35 & 3.33 \\
3 & 2.87 & 2.80 \\
4 & 2.61 & 2.49 \\
\hline \hline
\end{tabular}

geometries are shown in Fig. 5. For the last species, the computed SBEs for solvation in acetonitrile and the $\mathrm{IE}_{a}$ 's and $\mathrm{IE}_{v}$ 's are listed in Tables I and II, respectively. The SBEs of $\mathrm{Ba}\left(\mathrm{CH}_{3} \mathrm{CN}\right)_{1-4}$ clusters have also been corrected for BSSE through the counterpoise method. As shown in Table I, these corrections are on the order of 4-6 $\mathrm{kJ} \mathrm{mol}^{-1}$, which are lower than the precision of the theoretical methodology used here. The optimized geometries for the $\mathrm{BaNC}$ and the $\mathrm{BaCN}$ species are also shown in Fig. 5.

The present theoretical $\mathrm{IE}_{a}$ 's and $\mathrm{IE}_{v}$ 's for $\mathrm{Ba}\left(\mathrm{CH}_{3} \mathrm{CN}\right)_{n}$ clusters (Table II) support the finding that $\mathrm{Ba}\left(\mathrm{CH}_{3} \mathrm{CN}\right)_{1}$ is only observed at the photoionization energy of $4.66 \mathrm{eV}$ in a singlephoton absorption regime. Species with $n=2-4$ could also be ionized at the photon energy of $3.49 \mathrm{eV}$. The absence of mass peaks for $\mathrm{Ba}^{+}\left(\mathrm{CH}_{3} \mathrm{CN}\right)_{2-4}$, along with the single-photon ionization nature of the $\mathrm{Ba}^{+}\left(\mathrm{CH}_{3} \mathrm{CN}\right)_{1}$ detection, suggest that these are not produced in the cluster beam.

Under the present conditions, it is apparent that the clustering process is less efficient for neutral than for cationic clusters (cf. Figs. 1 and 4). From an experimental viewpoint, this can be justified by the absence of neutral complexes larger than $\mathrm{Ba}\left(\mathrm{CH}_{3} \mathrm{CN}\right)_{1}$ in the mass spectra, whereas charged species as large as $\mathrm{Ba}^{+}\left(\mathrm{CH}_{3} \mathrm{CN}\right)_{7}$ are readily observed. Theoretically, it is rationalized by the smaller SBEs for the most stable isomers of $\mathrm{Ba}\left(\mathrm{CH}_{3} \mathrm{CN}\right)_{1-4}$ clusters relative to those for $\mathrm{Ba}^{+}\left(\mathrm{CH}_{3} \mathrm{CN}\right)_{n}$ complexes (Table I) because of the charge-dipole interactions in the ionic species, which are stronger than the dipole induceddipole interactions at play in neutral clusters. This in turn explains the comparatively narrower cluster size distribution for neutrals (for which only the $n=1$ complex is observed) than for cationic species.

As for cationic clusters, the most stable $\mathrm{Ba}\left(\mathrm{CH}_{3} \mathrm{CN}\right)_{n}$ theoretical structures show a preference for the $\mathrm{N}$ atoms of acetonitrile molecules to coordinate to the Ba atoms (Fig. 5). The $\mathrm{Ba}\left(\mathrm{CH}_{3} \mathrm{CN}\right)_{1,2}$ clusters feature angular configurations, which differ from the linear geometries of the respective cluster cations (cf. Figs. 2 and 5). The geometries for $\mathrm{Ba}\left(\mathrm{CH}_{3} \mathrm{CN}\right)_{3,4}$ are similar to those of the $\mathrm{Ba}^{+}\left(\mathrm{CH}_{3} \mathrm{CN}\right)_{3,4}$ ions, the major difference being that the $\mathrm{Ba}\left(\mathrm{CH}_{3} \mathrm{CN}\right)_{3}$ and $\mathrm{Ba}\left(\mathrm{CH}_{3} \mathrm{CN}\right)_{4}$ clusters feature $\mathrm{N}-\mathrm{Ba}-\mathrm{N}$ angles between two closest $\mathrm{CH}_{3} \mathrm{CN}$ molecules of $69.0^{\circ}$ and $70.1^{\circ}$, respectively, which are lower than those found in $\mathrm{Ba}^{+}\left(\mathrm{CH}_{3} \mathrm{CN}\right)_{3,4}$. Consideration of chiefly $6 \mathrm{~s}-5 \mathrm{~d} \sigma$ hybridization of the $\mathrm{Ba}$ atoms is also required to explain the bonding in neutral clusters. This is to be expected from the ${ }^{1,3} \mathrm{D}$ states of Ba lying below their ${ }^{1,3} \mathrm{P}$ states. ${ }^{32}$ It is also confirmed by computing, via natural population analysis, the $s: d$ barium atom orbital contribution to the highest occupied molecular orbitals (HOMO's) of the $\mathrm{Ba}\left(\mathrm{CH}_{3} \mathrm{CN}\right)_{n}$ complexes (Fig. 6), which leads to the values of 0.92:0.00, 0.85:0.14, 0.76:0.17, and 0.59:0.19, for $n=1,2,3$, and 4, respectively.

Noteworthy, the SBEs of $\mathrm{Ba}\left(\mathrm{CH}_{3} \mathrm{CN}\right)_{n}$ complexes follow similar trends as the related cationic clusters, i.e., the SBE for $\mathrm{Ba}\left(\mathrm{CH}_{3} \mathrm{CN}\right)_{3}$ is lower than those for $n=1,2$, and 4 , which in turn are comparable in magnitude to each other. Based on previous arguments ( $\mathrm{Sec}$. III A), the $\mathrm{Ba}\left(\mathrm{CH}_{3} \mathrm{CN}\right)_{3}$ complex would be expected to have a low population, as compared to those for $n=1,2$, and 4, thereby leading to a bimodal $\mathrm{Ba}\left(\mathrm{CH}_{3} \mathrm{CN}\right)_{n}$ cluster size distribution. Unfortunately, corroboration of this 


\section{$\mathrm{Ba}\left(\mathrm{CH}_{3} \mathrm{CN}\right)_{1}$}

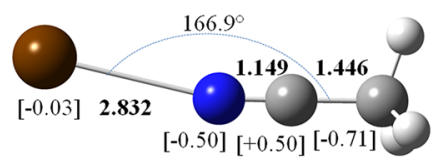

$\mathrm{Ba}\left(\mathrm{CH}_{3} \mathrm{CN}\right)_{3}$
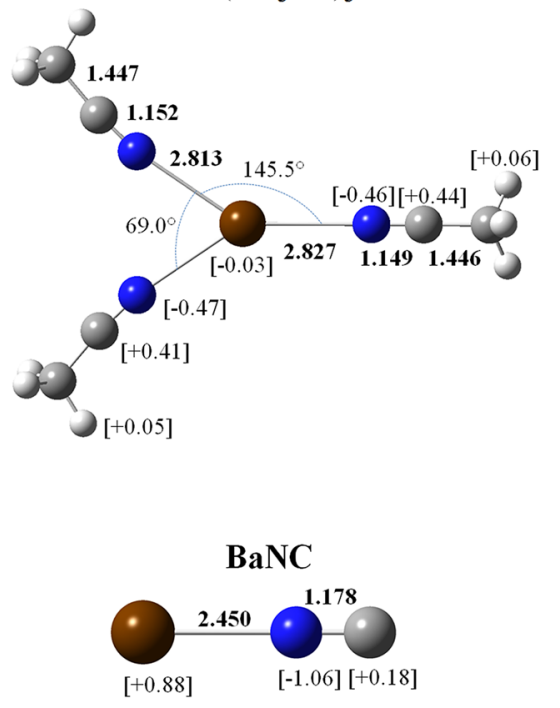

\section{$\mathrm{Ba}\left(\mathrm{CH}_{3} \mathrm{CN}\right)_{2}$}
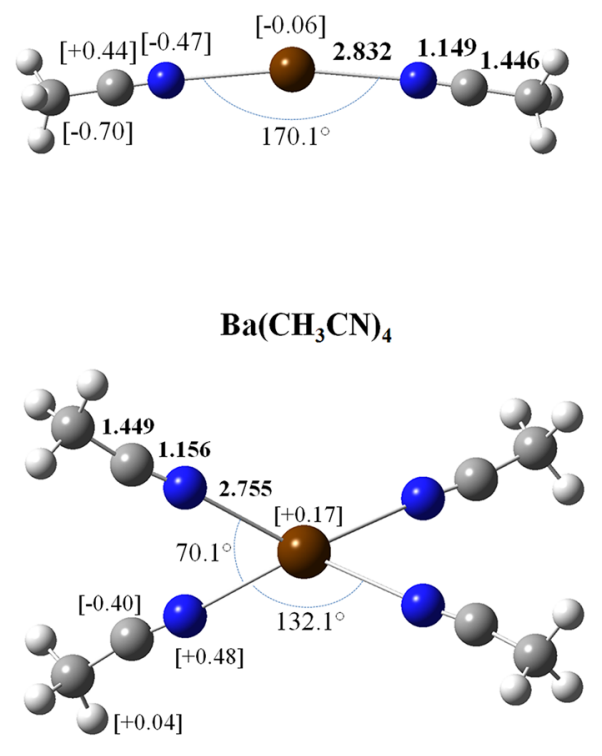

FIG. 5. Optimized structures for the lowest-lying energy isomers of neutral $\mathrm{Ba}\left(\mathrm{CH}_{3} \mathrm{CN}\right)_{1-4}$ clusters, as calculated at the $m$ PW1PW91 level. The bond lengths and the bond angles are given in angstroms and degrees, respectively. The results of natural population analysis at the DFT level are indicated in brackets. prediction was impossible here because of the narrow size distribution, where neutral clusters heavier than $\mathrm{Ba}\left(\mathrm{CH}_{3} \mathrm{CN}\right)_{1}$ are not produced.

\section{Born-Oppenheimer molecular dynamics of the cationic clusters}

To investigate the possibility that completion of the first solvent shell of $\mathrm{Ba}^{+}\left(\mathrm{CH}_{3} \mathrm{CN}\right)_{n}$ clusters at $n=2$ could be responsible for the relatively low intensity of the $n=3$ peak,
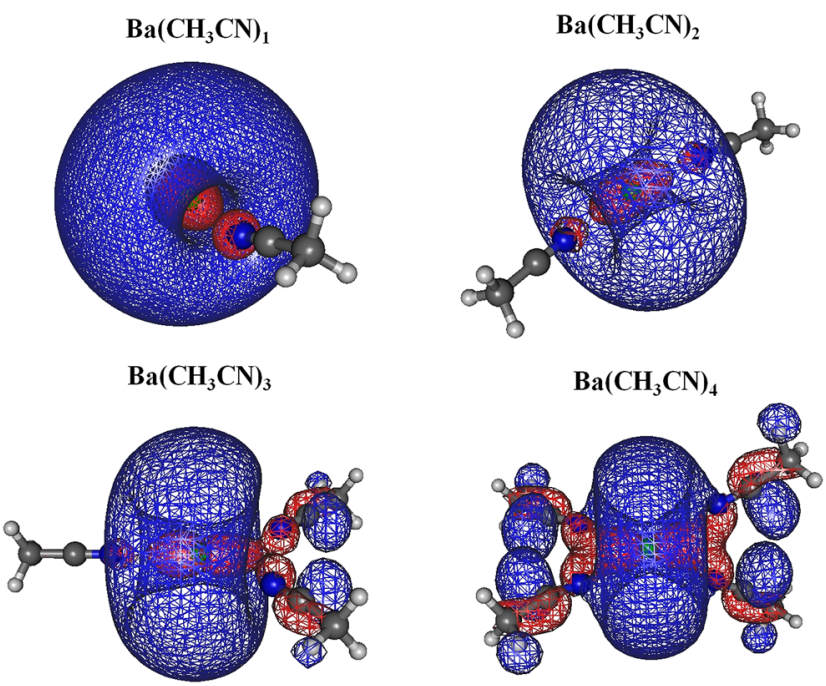

FIG. 6. Electronic density distributions of the HOMO's in the lowestlying energy isomers of $\mathrm{Ba}\left(\mathrm{CH}_{3} \mathrm{CN}\right)_{1-4}$ clusters. The iso-density surfaces correspond to $0.015 \AA^{-3}$.
Born-Oppenheimer Molecular Dynamics (BOMD) calculations were performed for $n=2-4$ starting from structures, on which two acetonitriles are directly bound to $\mathrm{Ba}^{+}$at $\mathrm{N}-\mathrm{Ba}-\mathrm{N}$ angles of around $70^{\circ}$, and the third and fourth $\mathrm{CH}_{3} \mathrm{CN}$ molecules for the $n=3$ and 4 clusters, respectively, are positioned in the second shell. The movies describing the temporal evolution of the structure for each cluster up to $700 \mathrm{fs}$ of simulation are presented as the supplementary material.

The temporal behavior of $\mathrm{Ba}^{+}\left(\mathrm{CH}_{3} \mathrm{CN}\right)_{2}$ at $298 \mathrm{~K}$ indicates that the ligands rearrange to achieve the expected linear geometry (Fig. 2), starting from an angular structure $\left(\mathrm{N}-\mathrm{Ba}-\mathrm{N}\right.$ angle $\left.=69.75^{\circ}\right)$ and passing through a quasi-linear geometry $\left(\mathrm{N}-\mathrm{Ba}-\mathrm{N}\right.$ angle $\left.=167.54^{\circ}\right)$ at $470 \mathrm{fs}$. The cluster visits the most stable geometry at the middle of the simulation, then oscillating around a quasi-linear geometry and further proceeding with a conformational change. The dynamics at $298 \mathrm{~K}$ are similar to those at 0 and $50 \mathrm{~K}$, the latter being a typical temperature of the species produced in cluster beam sources as the one used here, ${ }^{3}$ which suggests that at the present experimental conditions the $\mathrm{Ba}^{+}\left(\mathrm{CH}_{3} \mathrm{CN}\right)_{2}$ cluster fluctuates in the gas phase around two angular structures passing through the most stable geometry (the linear one).

The simulations for the $\mathrm{Ba}^{+}\left(\mathrm{CH}_{3} \mathrm{CN}\right)_{3,4}$ structures at $298 \mathrm{~K}$ also show the molecular re-arrangement to reach the most stable conformations of the corresponding cations (Fig. 2). At the end of each simulation, all of the nitrogen atoms are pointed to the barium ion, thereby stabilizing the positive charge over the metal. The $\mathrm{Ba}^{+}\left(\mathrm{CH}_{3} \mathrm{CN}\right)_{3}$ cluster reaches the pyramidal structure after $400 \mathrm{fs}$ of simulation, and at $650 \mathrm{fs}$, the geometry is quasi-planar converging to the most stable 
conformation. The convergence to the lowest energy conformation becomes slower as the cluster size increases, thereby demanding a lower time step to calculate the trajectory. The $\mathrm{Ba}^{+}\left(\mathrm{CH}_{3} \mathrm{CN}\right)_{4}$ cluster does not converge to the most stable conformation after $550 \mathrm{fs}$ of simulation. The final frames of the simulation indicate that the expected geometry, shown in Fig. 2, should be obtained at nearly $700 \mathrm{fs}$ of simulation. It is important to point out that the convergence of the first trajectory point for the $n=3$ cluster was more demanding than those for $n=2$ and 4, which is to be expected on the basis of the relatively low $\mathrm{SBE}$ for $\mathrm{Ba}^{+}\left(\mathrm{CH}_{3} \mathrm{CN}\right)_{3}$.

The results of BOMD calculations prevent considering the completion of the first solvent shell at $n=2$ as responsible for the relatively low intensity of the $n=3$ peak. Furthermore, they confirm the lowest energy structures for $\mathrm{Ba}^{+}\left(\mathrm{CH}_{3} \mathrm{CN}\right)_{2-4}$ clusters, as optimized in the DFT, time independent calculations.

\section{CONCLUSIONS}

The size distributions of neutral and cationic $\mathrm{Ba}^{x}\left(\mathrm{CH}_{3} \mathrm{CN}\right)_{n}$ $(x=0,+1)$ clusters have been derived from molecular beam experiments sequentially probing the two charge states, as produced by a standard laser vaporization-supersonic expansion pick-up source. All of the cluster size distributions were found to be unaffected by the variables controlling the performance of the cluster source. Under the present operational conditions, the clustering process seems to be more efficient for cationic than for neutral clusters, given the relatively wide distributions of the former, for which $n$ is in the range of 1-7, as compared to the latter where only the $n=1$ complex is observed. The distinct behavior is compatible with the expected charge-dipole interactions in the ionic species, which are stronger than the dipole induced-dipole interactions at play in neutral clusters, and it is corroborated by the relative magnitude of the theoretical SBEs for the lowest-lying isomers of neutral and cationic clusters with $n=1-4$, as computed at the density functional theory level.

The $\mathrm{Ba}^{+}\left(\mathrm{CH}_{3} \mathrm{CN}\right)_{1-7}$ family features a bimodal size distribution with an apparent minimum at the mass peak for $n=3$. The evidence was rationalized on the basis of the corresponding SBEs computed for $n=1-5$, from which it could be expected the $\mathrm{Ba}^{+}\left(\mathrm{CH}_{3} \mathrm{CN}\right)_{3}$ complex to have a low population, as compared to those for $n=1,2$, and 4 . The theoretical structures of the lowest-lying isomers for $n=1-4$ clusters are helpful to interpret the relative instability of $\mathrm{Ba}^{+}\left(\mathrm{CH}_{3} \mathrm{CN}\right)_{3}$ in terms of chiefly $6 s-5 \mathrm{~d} \sigma$ hybridization of the $\mathrm{Ba}^{+}$ions. In this picture, the interaction between the net dipole moment, which results from the arrangement of three acetonitrile molecules around the metal ion, and the induced quadrupole moment on $\mathrm{Ba}^{+}$, seems to be unfavorable and could be the reason for the relatively small third SBE. The finding that all of the ligands are coordinated to the $\mathrm{Ba}^{+}$ion in the lowest-lying $\mathrm{Ba}^{+}\left(\mathrm{CH}_{3} \mathrm{CN}\right)_{1-4}$ isomers, which is supported by BOMD simulations on such species, prevents considering completion of the first solvent shell as responsible for the relatively low intensity of the $n=3$ peak.

The present observations for $\mathrm{Ba}^{+}\left(\mathrm{CH}_{3} \mathrm{CN}\right)_{n}$ clusters have not been reported in previous studies on the $\mathrm{Mg}^{+}\left(\mathrm{CH}_{3} \mathrm{CN}\right)_{1-7}$ cluster size distributions, as produced in pick-up molecular beam sources under similar conditions as here. ${ }^{15}$ The theoretical structures of the lowest-lying isomers of $\mathrm{Mg}^{+}\left(\mathrm{CH}_{3} \mathrm{CN}\right)_{1-3}$ clusters suggest that the ligands are both located in the first solvation shell and equivalently positioned around the $\mathrm{Mg}^{+}$ion, which results in a steady decrease of the SBEs with increasing cluster size. More recently, the magic numbers at $n=3,6,9$, and 14 have been derived from $\mathrm{Mg}^{+}\left(\mathrm{CH}_{3} \mathrm{CN}\right)_{n \leq 18}$ cluster distributions, as produced running the pick-up sources at backing pressures of the pulsed valve in the range of 3-8 bars, though the origin of this behavior remains unclear. ${ }^{16}$

Based on the present computations for $\mathrm{Ba}\left(\mathrm{CH}_{3} \mathrm{CN}\right)_{n}$ clusters, the $\mathrm{Ba}\left(\mathrm{CH}_{3} \mathrm{CN}\right)_{3}$ complex is also predicted to have a low SBE, as compared to $n=1,2$, and 4, which could not be corroborated experimentally because neutral clusters heavier than $\mathrm{Ba}\left(\mathrm{CH}_{3} \mathrm{CN}\right)_{1}$ are not produced in the source, under the experimental conditions explored in this work. Yet, this will hopefully stimulate future experiments to study the stepwise hydration behavior of such neutral species.

\section{SUPPLEMENTARY MATERIAL}

See supplementary material for the optimized structures of the low-lying energy isomers of the $\mathrm{Ba}^{+}\left(\mathrm{CH}_{3} \mathrm{CN}\right)_{5}$ cluster featuring coordination numbers $(\mathrm{CN})$ of 5,4 , and 2 , for the electronic density distributions of the SOMO in the lowestlying isomer $(\mathrm{CN}=5)$ of $\mathrm{Ba}^{+}\left(\mathrm{CH}_{3} \mathrm{CN}\right)_{5}$ and the movies showing the results of Born-Oppenheimer Molecular Dynamics (BOMD) calculations performed on the $\mathrm{Ba}^{+}\left(\mathrm{CH}_{3} \mathrm{CN}\right)_{2-4}$ clusters at a temperature of $298 \mathrm{~K}$, and for $\mathrm{Ba}^{+}\left(\mathrm{CH}_{3} \mathrm{CN}\right)_{2}$, also at 0 and $50 \mathrm{~K}$.

\section{ACKNOWLEDGMENTS}

Financial support from CONICET, FONCyT, SeCyTUNC, and FAPERJ is acknowledged.

${ }^{1}$ M. Elhanine, L. Dukan, P. Maitre, W. H. Breckenridge, S. Massick, and B. Soep, J. Chem. Phys. 112, 10912-10925 (2000).

${ }^{2}$ N. Okai, H. Ishikawa, and K. Fuke, Chem. Phys. Lett. 415, 155-160 (2005).

${ }^{3}$ I. Cabanillas-Vidosa, M. Rossa, G. A. Pino, J. C. Ferrero, and C. J. Cobos, Phys. Chem. Chem. Phys. 14, 4276-4286 (2012).

${ }^{4}$ K. Hashimoto and K. Morokuma, J. Am. Chem. Soc. 116, 11436-11443 (1994).

${ }^{5}$ I. N. Tang, M. S. Lian, and A. W. Castleman, Jr., J. Chem. Phys. 65, 40224027 (1976)

${ }^{6}$ L. Operti, E. C. Tews, and B. S. Freiser, J. Am. Chem. Soc. 110, 3847-3853 (1988).

${ }^{7}$ M. H. Shen and J. M. Farrar, J. Chem. Phys. 94, 3322-3331 (1991).

${ }^{8}$ C. W. Bauschlicher, Jr., M. Sodupe, and H. Partridge, J. Chem. Phys. 96, 4453-4463 (1992).

${ }^{9}$ K. F. Willey, C. S. Yeh, D. L. Robbins, J. S. Pilgrim, and M. A. Duncan, J. Chem. Phys. 97, 8886-8895 (1992).

${ }^{10}$ N. F. Dalleska, B. L. Tjelta, and P. B. Armentrout, J. Phys. Chem. 98, 4191-4195 (1994).

${ }^{11}$ H. Watanabe, S. Iwata, K. Hashimoto, F. Misaizu, and K. Fuke, J. Am. Chem. Soc. 117, 755-763 (1995).

${ }^{12}$ H. Watanabe and S. Iwata, J. Phys. Chem. A 101, 487-496 (1997).

${ }^{13}$ W. Lu and S. Yang, J. Phys. Chem. A 102, 825-840 (1998).

${ }^{14}$ A. Andersen, F. Muntean, D. Walter, C. Rue, and P. B. Armentrout, J. Phys. Chem. A 104, 692-705 (2000).

${ }^{15}$ H. Liu, W. Guo, and S. Yang, J. Chem. Phys. 115, 4612-4619 (2001).

${ }^{16}$ E. H. Alsharaeh, Int. J. Mol. Sci. 12, 9095-9107 (2011).

${ }^{17}$ C. W. Bauschlicher, Jr., S. R. Langhoff, and H. Partridge, J. Chem. Phys. 94, 2068-2072 (1991). 
${ }^{18}$ G. Vitale, A. B. Valina, H. Huang, R. Amunugama, and M. T. Rodgers, J. Phys. Chem. A 105, 11351-11364 (2001).

${ }^{19}$ H. Koizumi, M. Larson, F. Muntean, and P. B. Armentrout, Int. J. Mass Spectrom. 228, 221-235 (2003).

${ }^{20}$ M. J. Frisch, G. W. Trucks, H. B. Schlegel, G. E. Scuseria, M. A. Robb, J. R. Cheeseman, G. Scalmani, V. Barone, B. Mennucci, G. A. Petersson et al., Gaussian 09, Revision A.02, Gaussian, Inc., Wallingford, CT, 2009.

${ }^{21}$ C. Adamo and V. Barone, J. Chem. Phys. 108, 664-675 (1998).

${ }^{22}$ I. S. Lim, H. Stoll, and P. Schwerdtfeger, J. Chem. Phys. 124, 034107 (2006).

${ }^{23}$ C. W. Bauschlicher, Jr., R. L. Jaffe, S. R. Langhoff, F. G. Mascarello, and H. Partridge, J. Phys. B 18, 2147 (1985).

${ }^{24}$ C. W. Bauschlicher, Jr., S. R. Langhoff, and H. Partridge, J. Chem. Phys. 84, 901 (1986).

${ }^{25}$ I. Cabanillas-Vidosa, M. Rossa, G. A. Pino, J. C. Ferrero, and C. J. Cobos, J. Phys. Chem. A 117, 4997-5006 (2013).
${ }^{26}$ O. W. Wheeler, D. R. Carl, T. E. Hofstetter, and P. B. Armentrout, J. Phys. Chem. A 119, 3800-3815 (2015).

${ }^{27}$ L. Baptista, D. P. P. Andrade, A. B. Rocha, M. L. M. Rocco, H. M. BoechatRoberty, E. F. da Silveira, E. C. da Silva, and G. Arbilla, J. Phys. Chem. A 112, 13382-13392 (2008)

${ }^{28}$ L. Baptista, D. P. P. Andrade, A. B. Rocha, M. L. M. Rocco, H. M. BoechatRoberty, and E. F. da Silveira, J. Phys. Chem. A 114, 6917-6926 (2010).

${ }^{29}$ M. Rossa, I. Cabanillas-Vidosa, G. A. Pino, and J. C. Ferrero, J. Chem. Phys. 136, 064303 (2012).

${ }^{30}$ C. W. Bauschlicher, Jr., S. R. Langhoff, and H. Partridge, Chem. Phys. Lett. 115, 124-129 (1985).

${ }^{31}$ CRC Handbook of Chemistry and Physics, Internet Version 2007, 87th ed., edited by D. R. Lide (Taylor and Francis, Boca Raton, FL, 2007), http:/www.hbcpnetbase.com.

${ }^{32}$ B. M. Miles and W. L. Wiese, At. Data Nucl. Data Tables 1, 1 (1969).

${ }^{33}$ V. Mikhailov, M. D. Wheeler, and A. M. Ellis, J. Phys. Chem. A 107, 4367-4372 (2003). 